\title{
Sinonasal inverted papilloma: 84 patients treated by endoscopy and proposal for a new classification*
}

\author{
A. Dragonetti ${ }^{1}$, R. Gera ${ }^{1}$, A. Sciuto ${ }^{2}$, A. Scotti ${ }^{1}$, A. Bigoni ${ }^{1}$, E. Barbaro ${ }^{2}$, A. \\ $\mathrm{Minni}^{2}$ \\ Unità Operativa Complessa di Otorinolaringoiatria, Ospedale S. Giuseppe, Milano, Italy \\ Dipartimento Testa e Collo Azienda Policlinico Umberto I, Università di Roma 'La Sapienza', Rome, Italy
}

\begin{abstract}
SUMMARY Aim: To suggest a new classification system for sinonasal papilloma based on a critical analysis of surgical indications and results obtained.

Methods: We analysed surgical data from 84 cases of sinonasal papilloma treated endoscopically,

Results: In 58 males and 26 females, between 25 and 85 years, the ethmoid sinus (63 cases), the maxillary sinus (43), and the nasal fossa (22) were mostly involved. No case of endocranial extension or carcinoma was reported. Complications were reported in $15.4 \%$ of patients, as well as 5 recurrences (5.9\%). Median follow up was 39,5 months.

To categorize the tumour for the most appropriate surgical treatment, we propose a classification based on 6 main categories that depend on the location, origin and extension of the tumour.

Conclusion: The classification that we propose presents advantages for prognosis and surgical indication in comparison with other classifications.
\end{abstract}

\section{INTRODUCTION}

The treatment of sinonasal papilloma is still a widely debated and a critical issue in otorhinolaryngology. Up until a few years ago, this 'benign' lesion was aggressively treated with external maxillectomy, due to its possible evolution and probable recurrences ${ }^{(1-3)}$. Since the 90 's, the rapid evolution of endonasal endoscopic techniques has revolutionized the surgical approach. In many series, this has allowed for extremely reliable results in comparative as well as absolute terms, both in the primary treatment of the lesion and recurrences ${ }^{(4-8)}$.

Despite the empowering of endoscopic tools and imaging techniques, the main problem in analysing outcomes in sinonasal papilloma surgery, and thus the subject of controversy, is the inability to accurately evaluate the stage of the disease. To properly validate endoscopic surgical techniques, it is of paramount importance to be able to objectively define the severity of the disease. Various classifications have been suggested by a number of authors ${ }^{(5,9,10)}$ but are not universally accepted. In our opinion, a classification should also provide indications as to the most suitable surgical treatment, to facilitate prognostic evaluation and a comparison of the results.
Though recurrences correlated with staging have been reported in the literature, for example, no correlation has been established between advanced stage, extension of the disease and increased recurrence rate ${ }^{(6)}$. Recently, a staging system was suggested, which intends to correlate the papilloma extension with a prognostic index, defined as a recurrence percentage ${ }^{(11)}$. It is mandatory to understand the pathological and radiological features as well as the natural history of sinonasal papilloma. The combination of factors such as location and extent of the tumour should determine the type of endoscopic technique and approach used for each individual case ${ }^{(12)}$. Staging must also be useful to ENT surgeons to define not only the endoscopic surgical technique but also the more radical external approaches, which may be required in cases in which the extension of the tumour has been underestimated, or that may be planned in combination with the endonasal endoscopic approach.

The aim of this paper is to suggest a new classification system based on a critical analysis of surgical indications and results obtained, to give a suitable tool for planning surgery. 


\begin{tabular}{lc}
\hline Site SP & $\mathrm{n}(\%)$ \\
\hline Ethmoid & $63(74.6 \%)$ \\
Maxillary & $43(50.7 \%)$ \\
Nasal Fossa & $22(26.8 \%)$ \\
Frontal & $8(9.8 \%)$ \\
Sphenoid & $7(8.4 \%)$ \\
\hline
\end{tabular}

Table 1a. Site and location of sinonasal papilloma (84 patients) Imaging and preoperative data.

\begin{tabular}{lc}
\hline Location IP & $\mathrm{n}(84$ patients $)$ \\
\hline Ethmoid & 44 \\
Maxillary sinus & 27 \\
Sphenoid & 4 \\
Frontal recess & 5 \\
Sphenoethmoidal reces & 7 \\
Frontal sinus & 3 \\
Not identified & 13 \\
\hline
\end{tabular}

Table $1 \mathrm{~b}$. Site of insertion of inverted papilloma (intraoperative findings). Note: multiple origins can occur.

\begin{tabular}{|c|c|c|c|c|}
\hline Extension & $\begin{array}{l}\mathrm{N}^{\circ} \text { of } \\
\text { patients }\end{array}$ & Type of resection & Complication & Recurrence \\
\hline $\begin{array}{l}\text { Nasal fossa and/or anterior or posterior } \\
\text { ethmoid and/or frontal recess and/or middle } \\
\text { turbinate and/or sphenoethmoid recess }\end{array}$ & 30 & $\begin{array}{l}\text { Ethmoid Centripetal Resection } \\
\text { (ECR) }\end{array}$ & Periorbital echymosis (4) & $1(3,3 \%)$ \\
\hline Sphenoid & 2 & ECR + sphenoidectomy & --------- & --- \\
\hline $\begin{array}{l}\text { Previous site (nasal fossa...) and involvment } \\
\text { of medial wall of maxillary sinus. }\end{array}$ & 39 & ECR + medial extended antrostomy & Periorbital echymosis (6) & $2(5.1 \%)$ \\
\hline $\begin{array}{l}\text { Inverted papilloma projecting into maxillary } \\
\text { sinus }\end{array}$ & 6 & $\begin{array}{c}\mathrm{ECR}+\text { medial and/or anterior } \\
\text { maxillectomy }\end{array}$ & $\begin{array}{c}\text { Epiphora (1) } \\
\text { Periorbital echymosis (1) }\end{array}$ & $1(16.6 \%)$ \\
\hline $\begin{array}{l}\text { Inverted papilloma exended to median por- } \\
\text { tion of frontal sinus }\end{array}$ & 5 & $\mathrm{ECR}+$ frontal osteoplasty Draf II-II & Frontal sinusitis (1) & $1(20 \%)$ \\
\hline \multirow[t]{2}{*}{ Extention to lateral portion of frontal sinus } & 2 & $\begin{array}{c}\text { Combined endoscopic and external } \\
\text { approach }\end{array}$ & & -- \\
\hline & 84 & & $13(15.4 \%)$ & $5(5.9 \%)$ \\
\hline
\end{tabular}

Table 2. Extension of the inverted papilloma and and type of resection performed (see text).

\section{MATERIALS AND METHODS}

\section{Study design}

This study provides a retrospective evaluation of 101 cases of Schneiderian papilloma (SP) treated endoscopically from September 1999 to December 2006 at the Department of Otorhinolaryngology of the S. Giuseppe Hospital in Milan and the Department of Neurology and Otorhinolaryngology of the 'Sapienza' University Hospital in Rome. They were broken down according to their histological type ${ }^{(13)}$ : 4 Exophytic Papilloma (fungiform), 84 Inverted Papilloma (IP), and 13 Oncocytic Papilloma. The 84 patients with IP were evaluated retrospectively, with particular reference to their demographic and medical history details, endoscopic and radiological data and details of the surgical procedure.

Preoperative management for IP consisted of nasal endoscopy, contrast-enhanced CT and MRI with gadolinium for a better diagnostic evaluation, and finally a biopsy. We performed multiple deep endoscopic biopsies of the lesion as a second diagnostic step, after examining the results of imaging. In the 5 days before surgery, the patient was administered antibiotic therapy (ampicillin/quinolones) and corticosteroids (30 mg prednisone/per day) to reduce concomitant inflammatory polyps and intraoperative bleeding. All surgical specimens were examined for cancerous microfoci in the IP.
The patients were evaluated postoperatively with $0^{\circ}$ and $30^{\circ}$ nasal endoscopy, and with MRI with gadolinium. The mean follow-up was 39.5 months (97 - 13 months). Follow-up was performed every 3 months the first year, every 4 months for the second year and every 6 months from the third year.

\section{RESULTS}

There were 58 males and 26 females, with an age ranging between 25 and 85 years (mean is 64 years). All patients had undergone an endoscopic evaluation and had biopsies positive for IP. The preoperative radiological study included contrast enhanced CT in every patient and MRI in 76 patients (90.5\%). Fourteen patients had been subjected to a first procedure in another hospital, 9 patients for SP and 5 for another disease. Six patients also had bilateral sinonasal polyposis.

Evaluation of the preoperative endoscopy and radiological data showed involvement of various sinonasal sites, as reported in Table 1 . The ethmoid sinus (63 cases), the maxillary sinus ( 43 cases), and the nasal fossa ( 22 cases) were mostly involved. The IP developed in the frontal sinus in 8 cases ( 1 bilateral) and in the sphenoid sinus in 7 cases. In 1 patient, the papilloma was located exclusively in the sphenoid. No case of endocranial extension was found, nor association with carcinoma. 


\begin{tabular}{|c|c|c|c|}
\hline Krouse (2000) & Han (2001) & Cannady (2007) & Dragonetti-Minni (2008) \\
\hline $\begin{array}{l}\text { T1: confined to the nasal } \\
\text { cavity }\end{array}$ & $\begin{array}{l}\text { Group I: limited to nasal } \\
\text { cavity, lateral nasal wall, me- } \\
\text { dial maxillary sinus, ethmoid } \\
\text { sinus, sphenoid sinus }\end{array}$ & $\begin{array}{l}\text { Group A: confined to nasal } \\
\text { cavity, ethmoid sinuses or } \\
\text { medial maxillary wall }\end{array}$ & $\begin{array}{l}\text { Type I: isolated tumour involving one } \\
\text { site in the nasal fossa. It may originate } \\
\text { from the nasal septum, anterior ethmoid, } \\
\text { posterior ethmoid, medial turbinate, } \\
\text { frontal recess or sphenethmoidal recess }\end{array}$ \\
\hline $\begin{array}{l}\text { T2: ostiomeatal complex } \\
\text { region, ethmoid, medial } \\
\text { maxillary involvement (with } \\
\text { or without nasal cavity } \\
\text { involvement) }\end{array}$ & $\begin{array}{l}\text { Group II: extension lateral to } \\
\text { medial maxillary wall with or } \\
\text { without group I criteria }\end{array}$ & $\begin{array}{l}\text { Group B: involvement of any } \\
\text { maxillary wall (other than } \\
\text { the medial wall), or frontal } \\
\text { sinus or sphenoid sinus }\end{array}$ & $\begin{array}{l}\text { Type II - the sphenoid is the primary } \\
\text { location. }\end{array}$ \\
\hline $\begin{array}{l}\text { T3: any wall of maxillary } \\
\text { sinus but medial, frontal } \\
\text { sinus, or sphenoid with or } \\
\text { without } \mathrm{T} 2 \text { criteria }\end{array}$ & $\begin{array}{l}\text { Group III: extension into } \\
\text { frontal sinus }\end{array}$ & $\begin{array}{l}\text { Group C: inverted papilloma } \\
\text { with extension beyond the } \\
\text { paranasal sinus }\end{array}$ & $\begin{array}{l}\text { Type IV - } \\
\text { Type IV a - tumour projecting into the } \\
\text { maxillary sinus without involving the } \\
\text { anterior wall; } \\
\text { Type IV b-tumour extending to the ante- } \\
\text { rior and /or inferior wall of the maxillary } \\
\text { sinus }\end{array}$ \\
\hline \multirow[t]{2}{*}{$\begin{array}{l}\text { T4: any extrasinus involve- } \\
\text { ment or malignancy }\end{array}$} & $\begin{array}{l}\text { Group IV: extension outside } \\
\text { sinuses }\end{array}$ & & $\begin{array}{l}\text { Type } \mathbf{V} \text { - tumour extending to the median } \\
\text { portion of the frontal sinus. The tumour } \\
\text { extends to the frontal sinus but only goes } \\
\text { as far as halfway into the orbital roof. }\end{array}$ \\
\hline & & & $\begin{array}{l}\text { Type VI - extension to the lateral portion } \\
\text { of the frontal sinus or with extranasal } \\
\text { extension to soft tissues without perior- } \\
\text { bital and/or dural and/or neighboring } \\
\text { (i.e intracranial) extraparanasal tissue } \\
\text { infiltration }\end{array}$ \\
\hline
\end{tabular}

Table 3. Staging systems for inverted papilloma.

The 84 patients were all treated endoscopically by one of 4 different senior otolaryngologists. In 2 patients, the endoscopy was combined with an external approach for the frontal sinus.

Table 2 shows the type of procedures performed: in $84.5 \%$ (71 cases) an endoscopic resection of the IP was performed by subperiostal anterior and posterior ethmoidectomy (ethmoid subperiostal resection: ESR) tailored to the tumour, with sphenoidotomy, frontal recess exploration and antrostomy.

Postperative complications were reported in $15.4 \%$ of patients: periorbital ecchymosis was reported in 11 cases; frontal sinusitis due to stenosis in a Draf III procedure was reported in 1 case; epiphora was reported in 1 case, though no post-operative obstruction of the naso-lacrimal duct was reported.

We observed 5 recurrences (5.9\%): 1 in the ethmoid, 3 maxillary and 1 ethmoid-frontal. The first 4 cases were treated endoscopically, while the fifth was treated by frontal nasalisation using an external approach. At the last available follow-up, all 84 cases of IP were free from disease.

\section{DISCUSSION}

Surgery has always been considered as the optimal treatment of IP. A conservative transnasal approach was initially adopted, but it resulted in frequent recurrences, ranging between 0 and $75 \%{ }^{(11,14)}$. Because IP is a multicentric disease, this may explain the high recurrence rate. Hyams showed that in most cases, the disease originated from a single lesion but then spread due to metaplasia of the adjacent mucosa ${ }^{(13)}$.

The observation that almost all recurrences occured within the previous operating field established the belief that the recurrence actually was a persistence of the disease due to incomplete removal and prompted the adoption of more radical surgical approaches, which would allow for more extensive resection of the tumour among healthy tissue ${ }^{(15,16)}$. Medial maxillectomy, performed by lateral rhinotomy or in ways that avoid an external incision like 'midfacial degloving' (17), septal translocation and the so-called 'Rouge-Denker procedure' became the most common approaches. Consequently, the recurrence rate was reduced $^{(1,18)}$.

In 1981, Stammberger documented the treatment of IP using only endonasal endoscopy ${ }^{(19)}$. Since then, several studies have appeared in the literature focusing on endoscopic treatment of IP ${ }^{(4,6,10,11,20)}$. With the acquisition of more positive experiences, the selection of extreme cases has given way to a broader range of indications ${ }^{(21,22)}$. Some authors have criticized the use of endoscopic resection because it is usually impossible to perform an 'en-bloc' resection; however, a radical resection does not necessarily depend on the removal of a single block but rather on the removal of diseased tissue together with a margin of normal tissue and this can often be equally achieved by an extensive piece-meal removal ${ }^{(20)}$. 
The key points in ensuring an adequate exenteration of the IP include maintaining the dissection in a subperiostal plane, identifying the insertions of the papilloma and drilling the underlying bone at the site of attachment to ensure a radical removal ${ }^{(4-23)}$.

The importance of drilling the bone is emphasized by that the bony tissue underlying the IP insertion has apparent irregularities, with evidence of osteitis ${ }^{(24)}$. Hence, the need to remove the IP with a margin of healthy mucosa. Performing intraoperative histology becomes indispensable to identify the site of origin and to confirm the completeness of resection ${ }^{(24,25)}$.

The so-called "piecemeal clearance", by means of a debrider is no less effective than en-bloc' resection. In some cases, it actually allows for a better visualization of the tumour site ${ }^{(6,27,28)}$, though according to some it may lead to underdiagnosis of carcinoma microfoci ${ }^{299}$. Our approach is to initially perform the debulking of the lesion at the level of the nasal fossa and ethmoid as far as is necessary, after which we define the margins of the dissection in the healthy tissue and treat the site of origin.

In our opinion, the main problem to value the efficacy of the treatment of IP, however, depends on the application of a classification suited to the particular biological behaviour of the tumour and the indication of a proper surgical treatment.

We have retrospectively analysed what was found at surgery and related it to site and IP extention so as to correlate tumour location with the most appropriate surgical treatment. In this regard we believe that a careful analysis of preoperative imaging (CT and MR) and endoscopy give enough information for a correct surgical plan ${ }^{(30,31)}$.

Previous classifications correlated either the site of onset and extension of the tumour like the TNM staging ${ }^{(9-32)}$, or site and extension with surgical procedure ${ }^{(10)}$.

In our experiences, successful endoscopic treatment depends on the appropriate and complete removal of the tumour according to a subperiostal resection, starting from the edges and going to the core (centripetal resection); we believe that a clinical classification must necessarily have this basis.

We thus propose a classification based on six main categories according to tumour site and extension (evaluated on imaging and clinical data), along with the relevant surgical procedure:

Type I - Isolated tumour involving one or more sites in the nasal fossa. It may originate from the nasal septum, anterior ethmoid, posterior ethmoid, medial turbinate, frontal recess or sphenoethmoidal recess (SER). Surgical treatment consists in an ethmoid subperiostal resection (ESR) tailored to the disease, with sphenoidotomy, medial antrostomy and frontal recess clearance; if IP is limited to the nasal septum, an en-bloc resection should be considered.

Type II - The sphenoid is the primary location. Previous surgical procedures are associated with subperiostal sphenoidectomy with possible drilling of the anterior and inferior wall of

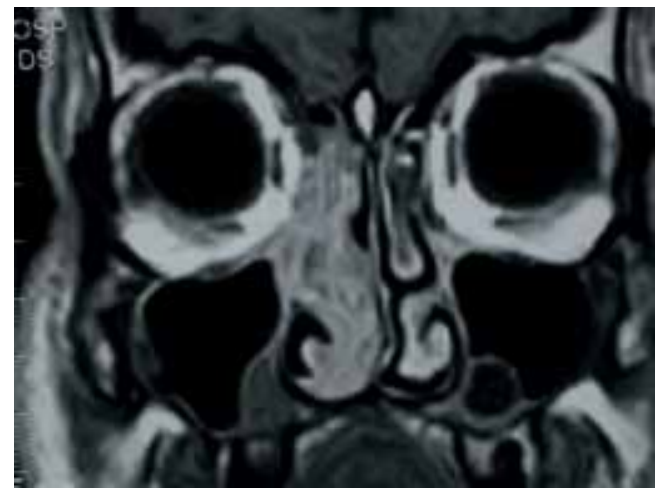

Figure 1. Sinonasal papilloma Type III.

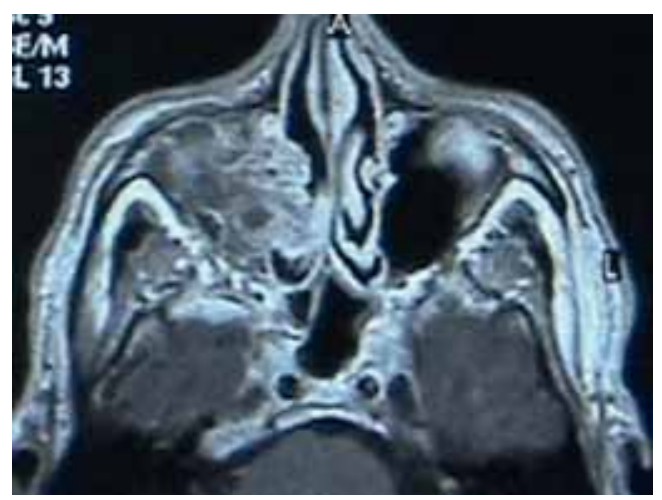

Figure 2. Sinonasal papilloma Type IVa.

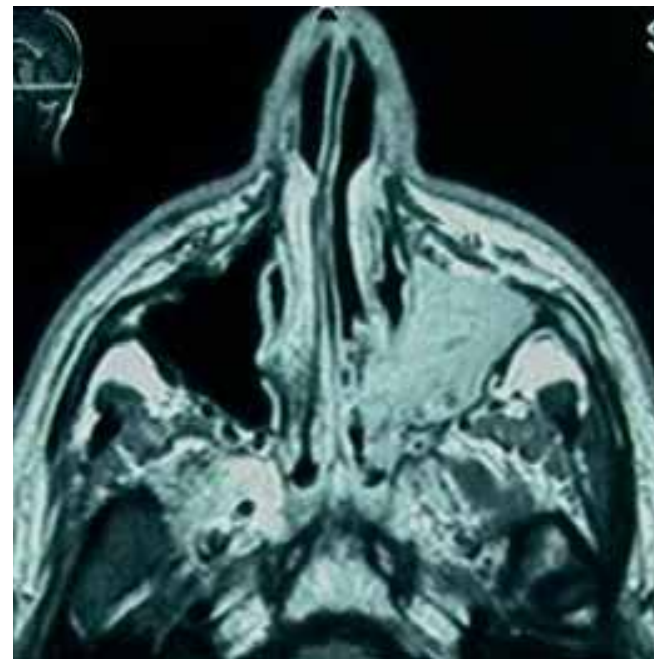

Figure 3. Sinonasal papilloma Type IVb.

the sphenoid.

Type III - Any site of origin in nasal fossa, ethmoid, sphenoid, medial turbinate, frontal recess or sphenoethmoidal recess with involvement of the maxillary sinus medial wall (Figure 1). Ethmoid subperiostal resection (ESR) tailored to the disease, with sphenoidotomy, medial antrostomy and frontal recess clearance associated with medial extended antrostomy, without nasolacrimal duct resection.

Type IV

Type IV a - Tumour projecting into the maxillary sinus without involving the anterior wall (Figure 2). Ethmoid subperiostal resection (ESR) tailored to the disease, with sphenoidotomy, medial antrostomy and frontal recess clearance associated 


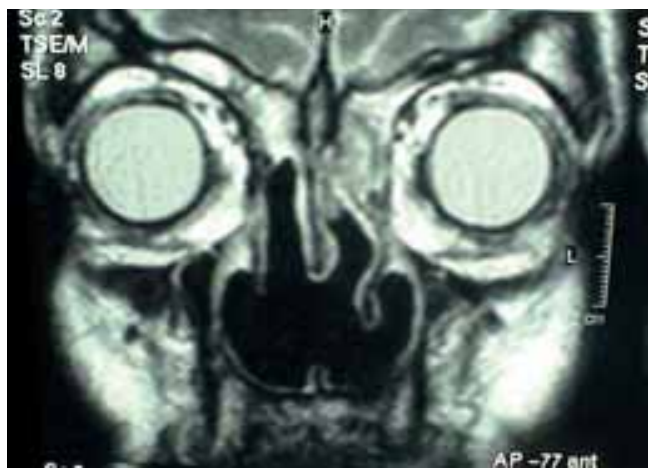

Figure 4. Sinonasal papilloma Type V.

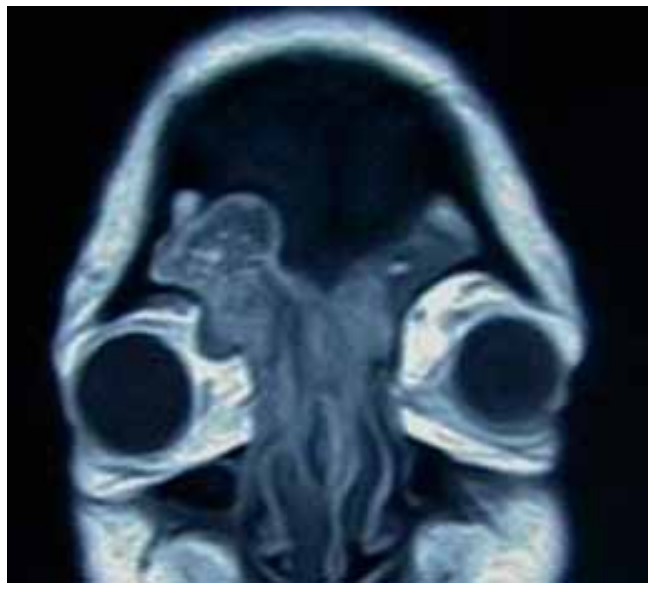

Figure 5. Sinonasal papilloma Type VI.

with endoscopic medial maxillectomy, according to Kraft (28): this procedure entails total resection of the lateral nasal wall including the anterior and posterior fontanelles, the inferior turbinate, and tissue from the pyriform aperture as well as the posterior wall of the maxillary sinus.

Type IV $\boldsymbol{b}$ - Tumour involving the anterior and /or inferior wall of the maxillary sinus (Figure 3). Ethmoid subperiostal resection (ESR) tailored to the disease, with sphenoidotomy, medial antrostomy and frontal recess clearance associated with endoscopic medial and anterior maxillectomy, with nasolacrimal duct resection. For this type, the quality of exenteration is identical both with endoscopic or with external approaches ${ }^{(33)}$. Type $\mathbf{V}$ - Tumour extending to the median portion of the frontal sinus. The tumour extends to the frontal sinus but only goes as far as halfway into the orbital roof (Figure 4). Previous surgical procedures (ESR) associated with frontal sinusotomy according to Draf II/III procedure; the anatomical-surgical requirement for this procedure is an anteroposterior diameter of the frontal sinus $>1 \mathrm{~cm}$.

Type VI - Extension to the lateral portion of the frontal sinus or with extranasal extension to soft tissues without periorbital and/or dural and/or neighboring (i.e. intracranial) extraparanasal tissue infiltration (Figure 5). Surgery comprises combined endoscopic and external approaches according to need. In the case of endocranial extension, craniotomy may be combined with endoscopic surgery. The involvement of facial skeleton soft tissues instead calls for the previously mentioned traditional surgical approaches (midfacial degloving).

A classification such as the one above presents obvious advantages. Compared to Krouse's and Han's classification, for example, the introduction of an additional class and of the relevant subclasses allows for a better and more homogeneous staging of SP. In our experience, it is rare to find IP confined to the nasal fossa ( $\mathrm{T} 1$ according to Krouse), while there are more cases involving the ethmoid and maxillary sinus (T2 according to Krouse). Hence the need for more flexible classification tools like types I-II-III-IV according to Dragonetti-Minni's classification (DM).

The primary involment of the sphenoid sinus calls for a separate group due to the different surgical approach (sub-periostal drilling). The extension to the medial wall of maxillary sinus may only require an extended antrostomy (type III DM) associated with ESR, which, as previously stated, comprises sphenoidotomy and frontal recess clearance. Because of its easier surgical control and lower recurrence rate, as well as the low incidence of primary localizations ${ }^{(24)}$, we separate the exclusive involvement of the ethmoid from that of the sphenoid, which we classify as III and treat with ESR associated with subperiostal sphenoidotomy. This distinguishes our classification from Han, who proposed a single group (I) and also allows for more flexible surgical planning.

Moreover, our clinical experience and a review of the literature have shown how, in terms of disease control and surgical procedure, there is a clearcut difference between the extension of the tumour to the maxillary sinus, which may require an extended antrostomy alone (type III), and the involvement into the lumen of maxillary sinus and/or anterior wall (type IVa, IVb); it is thus useful to keep the two groups separate, as rightly suggested by Krouse (T2-T3) and Han (Group I-II).

Another crucial point is the involvement of the frontal sinus, which we prefer to classify according to its mediolateral extension (type $\mathrm{V}-\mathrm{VI}$ ), as an indication of the possibility to treat it endoscopically or by a combined approach.

Ultimately, the classification, which we propose, presents obvious advantages in terms of prognosis and surgical indication. In our series, most cases (84.5\%) are of type I-II-III and have a better prognosis, while the remaining IV-V-VI types present a poorer prognosis or require more complex surgical techniques (Table 3). This classification in prognostic terms is consistent with Cannady's recent proposal ${ }^{(11)}$.

According to our experience, the approach to the maxillary sinus should always and exclusively be endoscopic. In the 39 type-III cases, we performed a medial extended antrostomy, and in the 6 type-IV cases, we performed medial endoscopic maxillectomy and/or an anterior procedure modified according to Sturmann and Canfield (21) to completely remove the tumour by drilling the bone wherever necessary. We should emphasize that in all type IVa cases, it was necessary to sacrifice the nasolacrimal duct and perform a marsupialization of the lacrimal sac. 
Naturally, the controversial point in endoscopic procedures is the treatment of the frontal sinus. Extension of the sinus and anatomical conditions permitting, we prefer to perform a Draf II or III-type frontal sinusotomy. This approach improves surgical exposure and enables conversion to an external procedure if required ${ }^{(26)}$. When the IP extends from the ethmoid and reaches the frontal sinus, it may not actually arise in the frontal mucosa, and may itself have created a 'spontaneous nasalization' such as to allow for adequate removal. We treated 4 patients according to this approach (type V), with an ethmoid-frontal recurrence.

The presence of IP on the lateral side of the sinus and its massive invasion (type VI), conversely rules out an endoscopic approach. In such cases, we perform a combined endoscopic and external approach (osteoplasty by coronal incision, or a more limited modified Lynch-type incision). Neither of the 2 cases treated, developed recurrence.

In our series, we did not have any case of IP with erosion of the skull base or endocranial extension. In none of our cases was an associated carcinoma found. Most recurrences occur up to two years post-operatively ${ }^{(3)}$, and the use of endoscopic evaluation facilitates their early identification. For this reason, the patient must be followed up regularly with nasal endoscopy, while radiological imaging techniques should be reserved for doubtful cases. In any case, IP should be followed up at regular intervals due to the possibility of late recurrences or metachronous carcinoma ${ }^{(34)}$.

\section{CONCLUSIONS}

To compare results obtained endoscopically with those of more traditional external approaches is very difficult, due to the lack of homogeneous series and classifications. Literature data and our experience, support an endoscopic approach, since the results are virtually the same as open procedures. Actually, in recent years indications have increased and endoscopic surgery has been extended to extensive and recurring IP ${ }^{(9-11,21)}$ with good results. We know well that a three-year follow-up would not be sufficient but we believe that the proposed classification may be helpful for surgical planning and if combined with long-term follow-up, could be useful for prognostic evaluation.

\section{REFERENCES}

1. Myers EN, Fernau JL, Johnson JT, et al. Management of inverting papilloma. Laryngoscope. 1990; 100: 481-490.

2. Thorp MA, Oyarzabal-Amigo MF, du Plessis JH, et al. Inverted papilloma: a review of 53 cases. Laryngoscope. 2001; 111: 1401-1405.

3. Lawson W, Ho BT, Shaari CM, et al. Inverted papilloma: A report of 112 cases. Laryngoscope. 1995; 105: 282-288.

4. Waitz G, Wigand ME. Result of endoscopic sinus surgery for the treatment of inverted papillomas. Laryngoscope. 1992; 102: 917-922.

5. Kamel RH. Conservative endoscopic surgery in inverted papilloma. Preliminary report. Arch Otolaryngol Head Neck Surg. 1992: 118; 649-653.

6. Busquets JM, Hwang PH. Endoscopic resection of sinonasal inverted papilloma: a meta-analysis. Otolaryngol Head Neck Surg.
2006; 134: 476-482,

7. Karkos PD, Fyrmpas G, Carrie SC, et al. Endoscopic versus open surgical intervention for inverted nasal papilloma: a systematic review. Clin Otorhynolaryngol. 2006; 31: 499-503.

8. Sautter NB, Cannady SB. Comparison of open vs endoscopic resection of inverted papilloma. Am J Rhinol. 2007; 21: 320-323.

9. Krouse JH. Development of a staging system for inverted papilloma. Laryngoscope. 2000; 110: 965-968.

10. Han JK, Smith TL, Loehrl T, et al. An evolution of the management of sinonasal inverting papilloma. Laryngoscope. Volume: 2001; 111: 1395-1400.

11. Cannady SB, Batra PS, Sautter NB, et al. New Staging System for sinonasal inverted papilloma in the endoscopic era. Laryngoscope. 2007; 117: 1283-1287.

12. Dubin MG, Sonnenburg RE, Melroy CT, et al. Staged endoscopic and combined open/endoscopic approach in the management of inverted papilloma of the frontal sinus. Am J Rhinology. 2005; 19: $442-445$.

13. Hyams VJ. Papillomas of the nasal cavity and paranasal sinues. A clinico-pathologic study of 315 cases. Ann Otol Rhinol Laryngol. 1971; 80: 192-206.

14. Harrison DFN, Lund VJ. Papillomas of the nasal cavity and paranasal sinuses. In: Harrison DFN, Lund VJ eds. Tumours of upper jaw. Edinburgh, London: Churcill Livingstone. 1993; 73-80.

15. Mc Cary WS, Gross CW, Reibel JF, et al. Preliminary report: endoscopic versus external surgery in the management of inverting papilloma, Laryngoscope. 1994; 104: 415-441.

16. Raveh E, Feinmesser R, Shpitzer T, et al. Inverted papilloma of the nose and paranasal sinues: a study of 56 cases and review of the literature. Isr J Med Sci. 1996; 32: 1163-1167.

17. Price JC, Holliday MJ, Johns ME, et al. The versatile midface degloving approach. Laryngoscope. 1998; 98: 291-295.

18. Phillips PP, Gustafson RO, Facer GW. The clinical behaviour of inverting papilloma of the nose and paranasal sinues: report of 112 cases and review of the literature. Laryngoscope. 1990; 100: 463-469.

19. Stammberger H. Zum invertierten papillom der nasnschleim haut. HNO 1981; 29: 128-133.

20. Lawson W, Kaufman MR, Biller HF. Treatment outcomes in the management of inverted papilloma: an analysis of 160 cases. Laryngoscope. 2003: 113; 1548-1556.

21. Tomenzoli D. Castelnuovo P, Pagella F, et al. Different endoscopic surgical styrategies in the management of inverted papilloma of the sinonasal tract: experience with 47 patients. Laryngoscope. 2004; 114: 193-200.

22. Lee TJ, Huang SF, Huang CC. Tailored endoscopic surgery for the treatment of sinonasal inverted papilloma. Head Neck. 2004; 26:145-153.

23. Wolfe SG, Schlosser RJ, Bolger WE, et al. Endoscopic and endoscope-assisted resections of inverted sinonasal papillomas. Otolaryngol Head Neck Surg. 2004; 113: 174-179.

24. Sukenik MA, Casiano R. Endoscopic medial maxillectomy for inverted papillomas of the paranasal sinues: value of the intraoperative endoscopic examination. Laryngoscope. 2000; 110: 39-42.

25. Tufano RP, Thaler ER, Lanza DC, et al. Endoscopic management of sinonasal inverted papilloma. Am J Rhinol. 1999; 13: 423-426.

26. Schlosser RJ, Mason JC, Gross CW. Aggressive endoscopic resection of inverted papilloma: an update. Otolaryngol Head Neck Surg. 2001; 125: 49-53.

27. McGarry GW, Gana P, Adamson B. The effect of microdebriders on tissue for histological diagnosis. Clin Otolaryngol Allied Sci. 1997; 22: 375-376.

28. Kraft M, Simmen D, Kaufmann T, et al. Long-term results of endonasal sinus surgery in sinonasal papillomas. Laryngoscope. $2003 ; 113 ; 1541-1547$.

29. Zweig JL, Schaitkin BM, Fan CY, et al. Histopatology of tissue samples removed using the microdebrider techniques: implications for endoscopic sinus surgery. Am J Rhinol. 2000; 14: 27-32.

30. Chiu AG, Jackman AH, Antunes MB, et al. Radiographic and histologic analysis of the bone underlyng inverted papilloma. Laryngoscope. 2006; 116: 1617-1620. 
31. Kamel R, Khaled A, Kandil T. Inverted papilloma:new classification and guidelines for endoscopic surgery. Am J Rhinol. 2005; 19 : 358-364.

32. Sadeghi N, Al-Dhahri S, Manukian JJ. Transnasal endoscopic medial maxillectomy for inverting papilloma. Laryngoscope. 2003; 113: 749-753.

33. Pasquini E, Sciarretta V, Farneti G, et al. Inverted Papilloma: report of 89 cases. Am Journal Otolaryngol. 2004; 25: 178-185.

34. Mirza S, Bradley PJ, Acharya A, et al. Sinonasal inverted papillomas: recurrences and sincronous and metacronous malignancies. J Laryngol Otol 2007; 121: 857-64.
Dr. Antonio Minni via Monti di Creta 30 00167 Roma

Italy

Tel +39-328-059 2302

Fax +39-06-3937 9100

E-mail: antonio.minni@uniroma1.it

The European Academy is seeking examiners to assist with the development and delivery of the rhinology component of the new European Academy Examination.

The requirements are shown below and applications should be made to : society@eaorl-hns.org.

MINIMUM REQUIREMENTS TO BECOME EXAMINER OF THE EBEORL-HNS BOARD

- At least five years clinical experience after receiving the title of specialist of ENT at a EU country or Fellow of the European Board of ORL-HNS

- Experience in training, teaching and examining in ORLHNS

- Submission of 3 guided questions and 5 MCQ to be evaluated by the EBE.

- Competency at spoken 'Medical' English

- Evidence of continuing professional development e.g. publications/presentations

- No more than 3 years after retirement from active medical practice

- Final decision will be at the discretion of the Board 